\title{
Research on the Strategy of Intension-type Development under the Background of Classification Management
}

\author{
Zhang Yan \\ Qifang Education Research Institute, Xi’an International University, Xi’an, Shaanxi, 710077
}

Keywords: classification management; private college and university; intension-type development

\begin{abstract}
Under the background of classification management, because of the particularity of running a top university and the complexity of the organization structure of a private college, the non-profit private colleges and universities should update the ideas of running schools, clarify the positions of running schools and cultivate the profound campus culture from the aspect of spiritual level that plays a leading role in running private colleges and university. In the institutional level that plays a guaranteed role, it is necessary to establish the modern university system, to establish the development mechanism that takes the discipline construction as the key factor, and to establish the student-oriented service mechanism. By means of establishing the guarantee system that can store abundant human resources and material resources, strengthening the construction of the guarantee system of teaching quality, carrying out applied scientific research and teaching research, and ensuring the construction of the basic function of the technical level, so as to realize the target of transforming development, intension-type development and characteristic development of private colleges and universities is proposed.
\end{abstract}

Private colleges and universities can choose to be a profit-making school or a non-profit school, and China carries out the classification management of private schools, which undoubtedly is the most important significance and breakthrough of the revised Private Education Promotion Law. This new law clarifies a large number of fuzzy non-profit and profit-making behaviors in the practice of private education, and reflects the mainstream of value of the Chinese Communist Party and the government of China for the development of private education.

In view of the particularity of the construction of high-level universities and the complexity of the organization structure of private colleges and universities, the connotative construction of non-profit private universities should be a whole which includes a spiritual level, an institutional level and a technical level. The three levels interact with each other and complement each other.

\section{Construction of the Spiritual Level that Plays a Leading Role}

The spiritual level of a high level university contains the ambitious idea, the lofty mission, the outstanding goal, the independent spirit, the advanced culture and the free innovation atmosphere and so on. It leads the construction of high-level universities on the basis of a high degree of self-consciousness.

It updating the educational concepts is an important prerequisite to establish high-level private universities.

First, it is necessary to insist on and carry forward the traditional spirit of the university. As the famous English educator Eric Ashby said----Any type of university is the product of heredity and environment. As a kind of academic institution and educational institution, university has a set of core idea system of "why university is university". Its fundamental aim is to pass on the knowledge, explore the unknown, serve the society and benefit mankind.

Second, it is necessary to insist on the idea of running school for public welfare. As an important part of higher education in China, the scholars and administrators of the private colleges and universities must bear in mind and carry out the mission of public welfare in running schools. The performance of this mission is directly related to the survival and development of the private colleges and universities. 
Third, it is necessary to establish the modern service idea. Education is a kind of "service", and the works of a school constitutes a service chain. We should take meeting the needs of the clients as the basic idea of running a school, and take this as the guidance to allocate the resources of the school to the clients. We should pay attention to the teaching quality, highlight the training characteristics, innovate the management process, improve the efficiency of running a school, so as to actualize the great-leap-forward development of the school.

Fourth, it is necessary to insist on the idea of running school that is pluralistic, characteristic and international. It is scientific and reasonable for the private colleges and universities, no matter what type they belong to, which level they choose, as long as they can take the best use of their own advantages, highlight their own characteristics, build their own brands, and promote the development of their schools. "What is suitable is the best".

Scientific and reasonable position is the precondition of sustainable development of private colleges and universities.

First, we should start from the overall arrangement and development situation of the higher education in China, and find the correct position of ourselves according to the needs of regional economic development and social progress, and by means of closing to the actual development of the industries and enterprises. And then, to combine the characteristics and advantages of our school, so as to choose the correct development direction, development goal, construction key point, setting up the proper majors accurately.

Second, we should pay attention to the transformation and development of the schools, realize the development of different position with the public colleges and universities, face the industries and enterprises, especially regional recently emergent industries and characteristic industries, train high-quality and applied technical talents for local economic construction and social development, and actively adapt to the transformation and development of being the applied technology colleges and universities.

Third, we should strengthen the classification guidance to the private colleges and universities according the different conditions of the schools in running schools; combine the conditions of the schools and the current situations of the schools so as to run schools in different level, in different majors and different types. We also should support the qualified private higher vocational schools to upgrade to undergraduate schools, support the high level private undergraduate schools to organize graduate education, so as to form the scientific overall arrangement that the private colleges and universities have their own characteristics and the different position in the development of the higher education in China.

Campus culture is the soul of a university, and it contains the historical accumulation, humanistic character and value concept that are formed during the long-term development of the university. To establish a first-class private university, we must highlight the cultural construction of the university, constantly optimize the academic and educational atmosphere, and create a fine cultural atmosphere for the cultivation of talents and the healthy and sustainable development of the school.

\section{Construction of the Institutional Level that Plays a Guaranteed Role}

The institutional level lies between the spiritual level and the technical level, which is the embodiment of the abstract spiritual level, which mainly includes the reasonable organizational structure, the perfect institution and the good implementation mechanism.

Improving the ability of government is the guarantee of sustainable development of the private colleges and universities. According to the requirements of modern university management system, we should actualize the transformation from management to governance, perfect the governance system, improve the scientific management level and core competitiveness.

First, it is necessary to formulate and improve the regulations of colleges and universities, in which we should make clear the corporative governance structure, internal operating mechanism, development directions, objectives of the schools, etc, and then strictly abide by the rules and regulations.

Second, it is necessary to implement the principal responsibility system under the leadership of 
the board of trustees, to guarantee the board's decision-making function and the management function and the command function of the principal, to perfect the staff of the board of trustees, to introduce the industry (enterprise) representative and the social representative to the staff of the board.

Third, it is necessary to establish and improve the professional academic organizations such as academic committees, degree committees, professors' committees, and other professional academic organizations; meanwhile, we should ensure the function of the academic power in the works of schools' management, so as to ensure that all aspects of schools' management are more professional, and to ensure and the rights of the experts in running schools and the autonomy of the schools.

Most private colleges and universities in China were founded in the 1980s, they have not established for a long time. Most of them follow the needs of the market and the society, the employment of the students is their aims. It is impossible to mention discipline construction; even the basic major construction is very weak. This is an important obstacle to the construction of high-level private universities. While generally carrying out major construction, the high level private colleges and universities should strengthen the construction of the key disciplines which is preparing to apply for master or doctor degrees, and take these disciplines as the leading program in the development of the school, so as to form the comprehensive development mechanism that the disciplines and the majors develop harmoniously.

(1) Defining the position of discipline development

A high level private university should develop and improve the disciplines and majors that are closely related to the needs of the society and that could strengthen the construction of the structure of the school's disciplines and majors.

First, the developmental goal and position of the private colleges and universities are to cultivate high-quality applied undergraduate talents, and to prepare for the cultivation of the talents who aim for applied professional master degree at the same time. Applied undergraduate education should be based on applied disciplines which is different from traditional academic disciplines.

Second, the position in aspect of service of the disciplines' development mainly is to serve the regional economic and the development of society, and to create conditions for national strategies. At present, the main national strategies are the western development strategy and the Belt and Road strategy which should be the service directions of the private colleges and universities in national level. In order to service for regional or local economic and social development, the main directions are the modern manufacturing, modern services, modern agriculture, and forestry etc.

(2) Building a good ecological environment of disciplines and majors inside and outside the schools

The most important condition for building a good ecological environment of disciplines and majors inside and outside the colleges and universities is that the private colleges and universities should fully understand the position and function of the disciplines and majors in the construction of a high-level private university, and make the scientific development plans and implementation plans, as well as the relevant institutional systems.

(3) The centre of developmental strategy of the high level private colleges and universities should be to improve their ability so as to promote the development of society and to promote their own development. In order to improve the dual ability of promoting social development and their own, the private colleges and universities must reform and optimize the structure of their disciplines and majors.

Talent cultivation is the main business of private colleges and universities. Under the guidance of service consciousness, we must boldly promote the teaching reform, follow the rule of people foremost, and promote the innovation on the model of talent cultivation.

First, it is necessary to persist in the development of students' personality and pay attention to the cultivation of their habits. We should give priority to the cultivation and development of the students, pay attention to the cultivation of students' good habits, and improve the students' comprehensive quality. In addition, we must reform the backward mechanism bravely, and construct a new knowledge system to serve the individual development of students. Under the 
background of the popularization of higher education, for the public, the purpose of receiving higher education is diversified. So we need to deep the reform according to the requirements for the healthy growth of the students, so that we could cultivate more talents with diversified characteristics, to the contrary, the individualized demands of the students also can be satisfied.

Second, it is necessary to create excellent lessons, and constantly improve the quality of teaching. By strengthening classroom management, improving teachers' structure, reforming teaching contents, teaching methods and so on, we can cultivate and strengthen students' interests and enthusiasms in learning, and improve the effectiveness of teaching and learning.

Third, it is necessary to establish a perfect multi-channel student service platform, to strengthen and improve the guidance for students' development, and student management as well, and to provide reliable guarantee for students' growth and individualized development.

\section{Construction of the Technical Level that Plays a Fundamental Role}

The technical level, also known as the physical level, can be divided into two levels. One is input, which mainly includes adequate funds; perfect facilities; first-class teaching staff; a competent, harmonious, efficient management team; and the outstanding headmaster who is wise and ambitious, etc. The second is output, including the quality of talent cultivation, scientific research level and contributions to society. Input is the foundation, is the guarantee; while output is the goal, and is the core. The construction of technical level should not only focus on input but also output, which is the main criterion of a high-level university.

To create a high level private university, we must have stable human resources and material resources guarantee system. The construction of human resources includes: (1) Strengthening the construction of teachers' team, it is the key to the sustainable development of the school. (2) Strengthening the cultivation of the managerial cadres, it is the important guarantee to realize the goal of development of the school. The construction of material resources includes: (1) establishing a stable funding guarantee mechanism; (2) strengthening the conditions of running school.

For most private colleges and universities, the goal of cultivating applied and skilled talents should be clearly defined, and the cultivation specifications and requirements should be defined from the perspective of comprehensive improvement of knowledge, ability and quality. It is necessary to balance the relationship between the liberal studies with the professional education, to highlight the interdisciplinary education from the perspective of overall optimizing the knowledge structure of students and their curriculum system; at the same time, it is necessary to pay more attention to systematization, foresight and practicability, and constantly update the teaching contents. We also should pay more attention to students' independent thinking ability, problem consciousness and critical spirit, develop their ability of analyzing and solving problems, arrange teaching practices and vocational skill trainings scientifically, and improve students' practical ability.

Private colleges and universities still have some advantages such as technology innovation, research on philosophy and social science, applied research, and scientific and technological resources sharing between colleges and enterprises. Therefore, the research of private colleges and universities should be based on applied research, promote the combination of industry, education and research; at the some time, it is necessary to actively participate in the decision-making consultations of government and enterprise and carry out forward and strategic research.

In short, the spiritual level provides the ideological basis for the institutional level and technical level, and it occupies the core position; the institutional level restrains and standardizes the construction and improvement of the spiritual level and the technical layers, as well as the intermediary of transforming thought into action; The technical level provides the material basis for the institutional and spiritual levels and it is the external expression and the carrier of the spiritual level and institutional level. Only from these three dimensions can we better realize the goals of transformation development, Intension development and characteristic development. 


\section{Acknowledgment}

Scientific Research Program that is Funded by Shaanxi Provincial Education Department "Research on the construction and Intension-type development strategy of the high level private universities in Shaanxi Province” (Program No. 13JZ075); Scientific Research Program that is Funded by Shaanxi Provincial Education Department "Research on the Characteristic Position and

Development Strategy of the Private Colleges and Universities in Shaanxi during the Transformation Period” (Program No. 15JZ055).

\section{References}

[1] Dong Yunchuan, Luo Zhimin. High level University Construction: a New Framework and Method[J]. Higher Education Research, 2015(6): 49-55.

[2] Fan Jixuan. Discussion on the Structural Elements of Intension-type Development Strategy of High level Private Universities[J]. Journal of Huanghe Science and Technology University, 2013(1): 2.

[3] $\mathrm{Xu}$ Xuqing. Some thoughts on the Construction of State-level top Private Colleges and Universities[J]. Research in Education Development, 2012, 07: 24-27.

[4] Shi Meng, Xia Jiting. On Modern University system and Construction of High level Private University[J]. China Adult Education, 2013, 01: 45-48.

[5] Wang Lei. Significance and ways of establishing a High level Private University[J]. China Adult Education, 2015, 04: 13-15. 